\title{
AN EXPERIMENTAL INVESTIGATION OF TURBULENT NATURAL CONVECTION IN AIR AT LOW PRESSURE ALONG A VERTICAL HEATED FLAT PLATE
}

\author{
CHARLES Y. WARNER* and VEDAT S. ARPACI $\dagger$
}

(Received 19 April 1967 and in revised form 7 August 1967)

\begin{abstract}
An experimental investigation of turbulent natural convection in air is described. The results of this study show good agreement with early investigations and remarkable agreement with the analytical correlation of Bayley [4]:

$$
N u=0 \cdot 10 R a^{3}
$$

for Rayleigh numbers up to $10^{12}$.

Extensive measurements of the temperature field indicate a good similarity in the tempcrature profilcs when compared on the basis of the natural coordinate $y$. The use of power law temperature profiles is shown to be undesirable for the case of turbulent natural convection.
\end{abstract}

\section{NOMENCLATURE}

g, acceleration of gravity;

$G r_{x}$ Grashof number based on plate length $x, G r_{x}=\beta \theta_{w} x^{3} g / v^{2}$;

$h$, film coefficient, average over length $x$;

$k$, thermal conductivity;

$m$, power-law constant;

$N u_{x}$ average Nusselt number based on plate length $x, N u_{x}=\bar{h} x / k$;

$R a_{x} \quad$ Rayleigh number based on plate length $x$;

$T, \quad$ temperature at any point $(x, y)$;

$T_{w}, \quad$ wall temperature;

$T_{\infty}$, ambient temperature;

$x$, distance downstream from leading edge ;

$y$, distance normal to plate surface.

\section{Greek symbols}

$\beta, \quad$ coefficient of thermal expansion;

$\delta, \quad$ thickness of viscous boundary layer;

\footnotetext{
* Assistant Professor of Mechanical Engineering, Brigham Young University, Provo, Utah, U.S.A.

$\dagger$ Professor of Mechanical Engineering, University of Michigan, Heat Transfer Laboratory, Ann Arbor, Michigan, U.S.A.
}

$\delta_{h}$, thermal displacement thickness [equation (1)];

$\theta, \quad$ temperature difference $\left(T-T_{\infty}\right)$;

$\theta_{w}, \quad$ wall temperature difference $\left(T_{w}-T_{\infty}\right)$;

$v$, kinematic viscosity.

\section{INTRODUCTION}

THE PHENOMENON of natural convection has some empirical meaning to even the most casual observer. A plume of smoke, rising through a short laminar trajectory, can easily be seen to undergo transition to the random motion of turbulence.

Laminar natural convection past a vertical plate has been adequately treated $[1,2]$. Although the turbulent case is much more important practically; because of its complexity, it has received less attention in the literature. Analytical attempts based upon the von Kármán-Pohlhausen integral formulation [3-5] give some information, but the results of these are not in complete agreement. Likewise, the experimental heat-transfer data and recommended correlations reported by various authors [5-8] lack full correspondence.

The importance of the behavior of cryogenic 
fluids in missile tanks has made a more complete understanding of the mechanism of turbulent natural convection very desirable. However, very little has been reported to date regarding the local mean temperature and velocity fields within the turbulent natural convection boundary layer. The physical nature of this layer has effectively obstructed measurements. The accurate measurement of temperature demands a refined technique. due to the weak velocity field [9], while that of the velocity presents great difficulties by conventional means [10] and is very costly in time and labor otherwise [11].

Extensive measurements of the heat-transfer relationships and temperature field for the natural convection of air past a vertical isothermal plate are reported herein. Good agreement is found with the experimental results of Saunders [6]. The analytical results of Baylcy gives a remarkably good correlation of the heat-transfer data. His relation is

$$
N u=0 \cdot 10 R a^{\frac{1}{3}} .
$$

\section{APPARATUS}

The working fluid chosen for the present experiment was air at atmospheric pressure. While providing the advantages of good visualization characteristics and a relatively thick boundary layer, it required that the heated flat plate used be of large physical size, especially in the vertical dimension. A single aluminum plate $\frac{1}{2} \times 24 \times 146$ in (thick, wide and tall. respectively) was subdivided into test sections 6-in tall by 12-in wide, by means of slots cut from the back side, leaving a full-length vertical guard heating section 6-in wide along either side. Heat was supplied to the plate by electrical strip heaters in good thermal contact with the back side of the plate. Two thick layers of glass-fiber insulation were used to reduce heat loss from the rear of the plate. Figure 1 presents a schematic representation of the basic apparatus.

To overcome the difficulties experienced by previous investigators due to sidewise entrainment of air on narrow plates [3,12], the approaching flow was completely enclosed in a plywood box of dimensions such that the plate and the air space within $10 \mathrm{ft}$ from and $1 \mathrm{ft}$ below it was isolated from the surroundings. Cool air entered the far end of the box through screened full-height slots in the sides. The hot boundary layer was allowed to exit through an appropriate opening near the plate in the ceiling of the box.

The plate surface was polished to a nominal roughness of less than $15 \mu$-in R.M.S. after mounting. The emissivity was measured and found to be uniform within a few per cent over the test surface. The plate leading edge consisted of a $30^{\circ}$ wedge with a vertex of $\frac{1}{16}$-in nominal radius. with its smooth surface coplanar with the surface of the main plate.

Platc temperature was measurcd by fifty copper-constantan couples with hot junctions imbedded near the test surface, and was maintained uniform to within $0.5 \mathrm{degF}$ for each test by regulating the power supplied to the individual heaters. Ambient air and enclosure surface temperatures were measured by similar thermocouples appropriately mounted.

The temperature field within the boundary layer itself was measured by a Chromel-constantan thermocouple constructed by performing a $0 \cdot 1$-in lap-weld of two 0.0005 -in dia. wires. The couple thus formed was welded to appropriate support wires of larger diameter. This procedure was utilized to assure good probe-tofluid contact, while minimizing the effect of conduction in the probe leads. Details of probe construction and an analysis outlining the basic design considerations are given elsewhere [9]. Radiation corrections calculated for the probe configuration adopted were found to be of the same order as the uncertainty in the wall temperature; these were therefore ignored in the reduction of data.

Probe position was remotely controlled by means of an clectric motor-driven carriage assembly. The distance between the probe and 


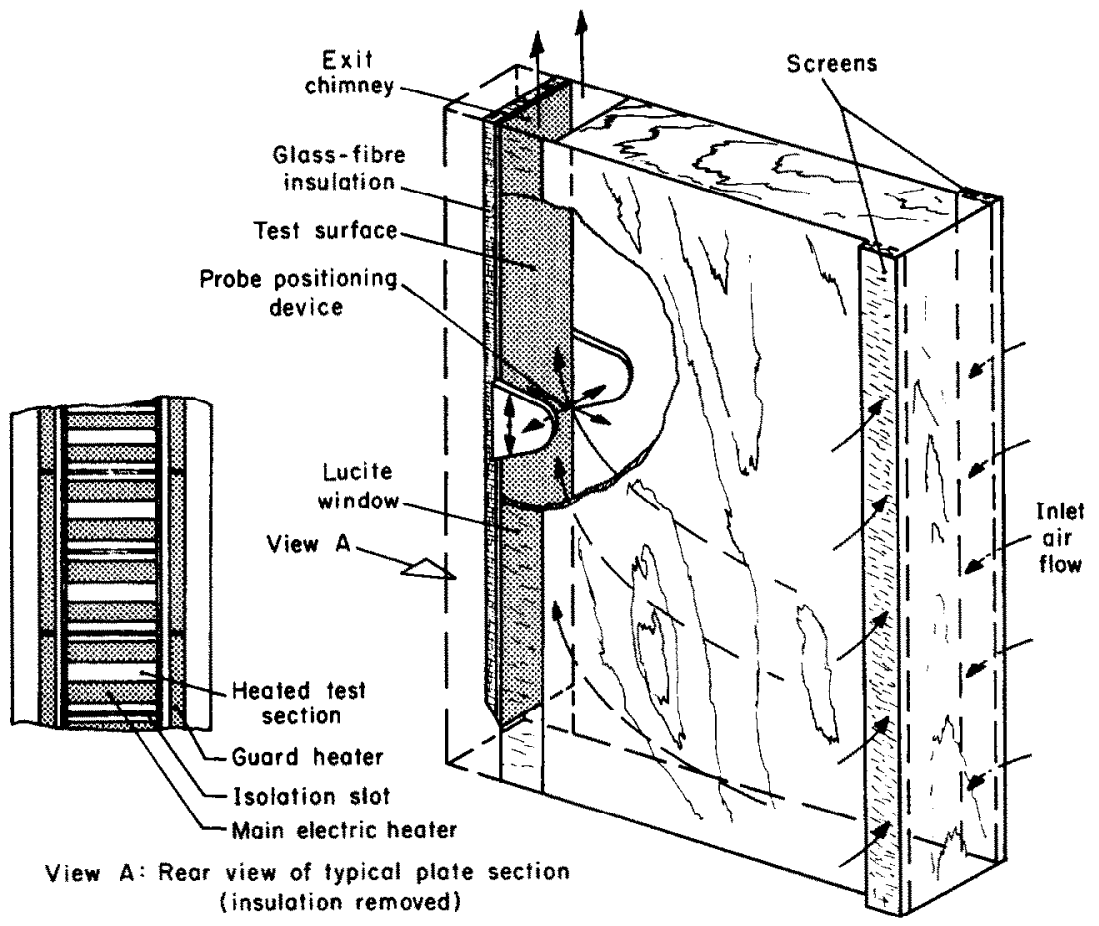

FIG. 1. Experimental apparatus.

the plate surface could be regulated and measured to the nearest 0.0002 in for distances up to 1 in by a mechanical dial micrometer which was viewed telescopically. Over the remaining 11 in of probe travel, an electrical indicator gave position to the nearest 0.006 in.

The entire apparatus was contained within an enclosed room especially constructed and sealed to eliminate extraneous air currents.

\section{VERIFICATION OF APPARATUS}

Actual measurements verified that the temperature field resulting from the enclosure configuration was two-dimensional over the test section of the plate, exhibiting uniform temperature within 3 per cent across the plate width in both the laminar and turbulent regimes.

The efficiency of the measures introduced to eliminate early transition to turbulence in the boundary layer was verified by smoke-trace studies; the high degree of control possible in this situation gave visual indication of critical Grashof numbers eight to ten times the expected value of $4 \times 10^{8}$. Although this suggested that even firmer controls would enable the transition to be further retarded, a complete investigation of this was not made.

The position of transition on the plate is indicated from the local heat-transfer data shown later in this paper (see Fig. 10).

The results of further evaluation of apparatus performance and a critical test for the airtemperature probe was very satisfactory. Temperature measurements in the laminar boundary layer were compared to the Pohlhausen-Ostrach similarity solution with excellent agreement.

Temperature fluctuations were found to be of the order of 10 per cent during the tests, when measured at the highest instrument sensitivity. To accurately determine the mean temperature, a large amount of damping was 
introduced into the instrument, and averages over a period of from 1 to $5 \mathrm{~min}$ were recorded.

\section{RESULTS: THE TEMPERATURE FIELD}

Figure 2 presents the results of temperature measurements within the fully turbulent range, corrected for thermocouple calibration. It is interesting to notice that the primary effect of increased distance $x$ is the extension of the thermal layer deeper into the ambient, with all temperature profiles retaining the same basic shapes for moderate distance from the wall.

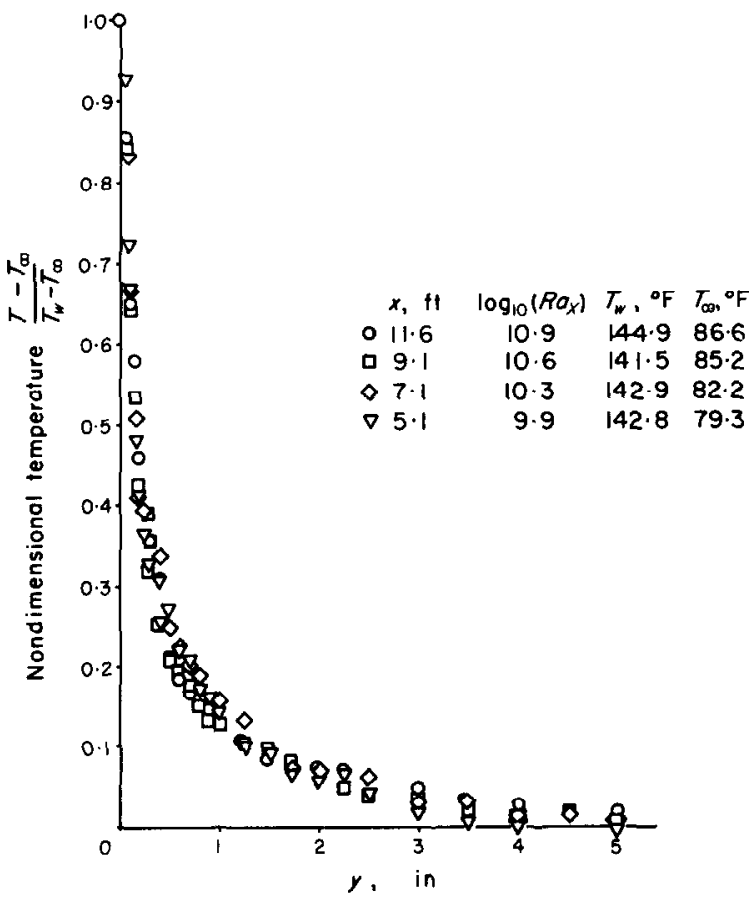

FIG. 2. Experimental turbulent temperature field.

Results of measurements very near the wall over the range of turbulent Rayleigh numbers investigated are reported in Fig. 3. A direct comparison with the power-law profile recommended by Eckert and Jackson [3] is made in Fig. 4. The natural coordinate is here normalized by a thermal displacement thickness defined as:

$$
\delta_{h}=\frac{1}{T_{w}-T_{\infty}} \int_{0}^{\delta}\left(T-T_{\infty}\right) \mathrm{d} y .
$$

This thickness could readily be calculated for both the theoretical power-law profile

$$
\theta / \theta_{w}=1-(y / \delta)^{1 / m}
$$

and for the experimental measurements. [Note that from equation (1), $\delta$ may be taken arbitrarily large, so long as the thermal effects are included.]

For the power-law profiles it may be easily shown that

$$
\delta_{h}=\delta /(m+1) .
$$

Figure 4 gives graphic demonstration of the poor approximation provided by equation (2) for the special case where $m=7$. It can easily be shown that other power laws give equally poor representation [9]. Of course, no power law is strictly valid at the wall.

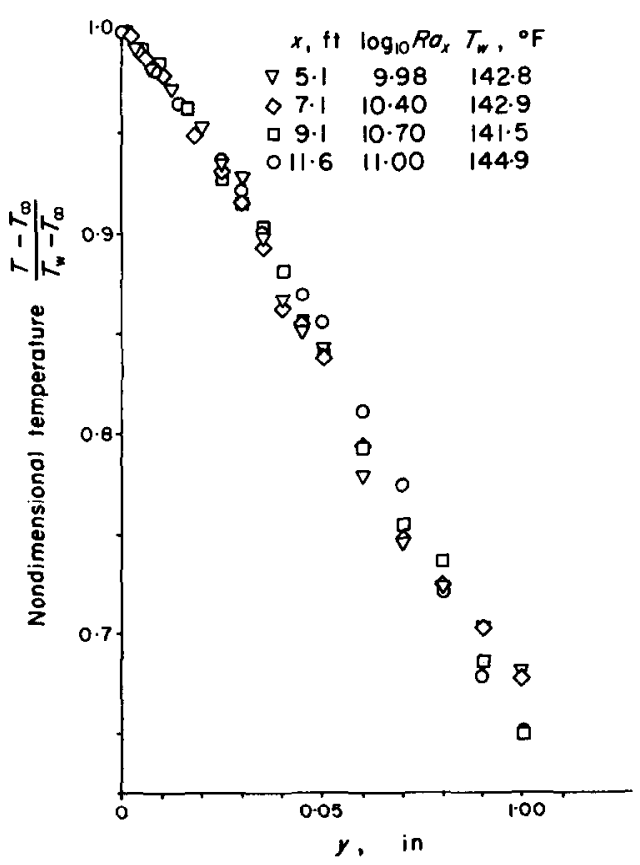

Fig. 3. Turbulent temperature field very near wall. 
It is probably appropriate here to digress momentarily into the historical background of equation (2). It has been suggested as a good representation of the data of Griffiths and Davis

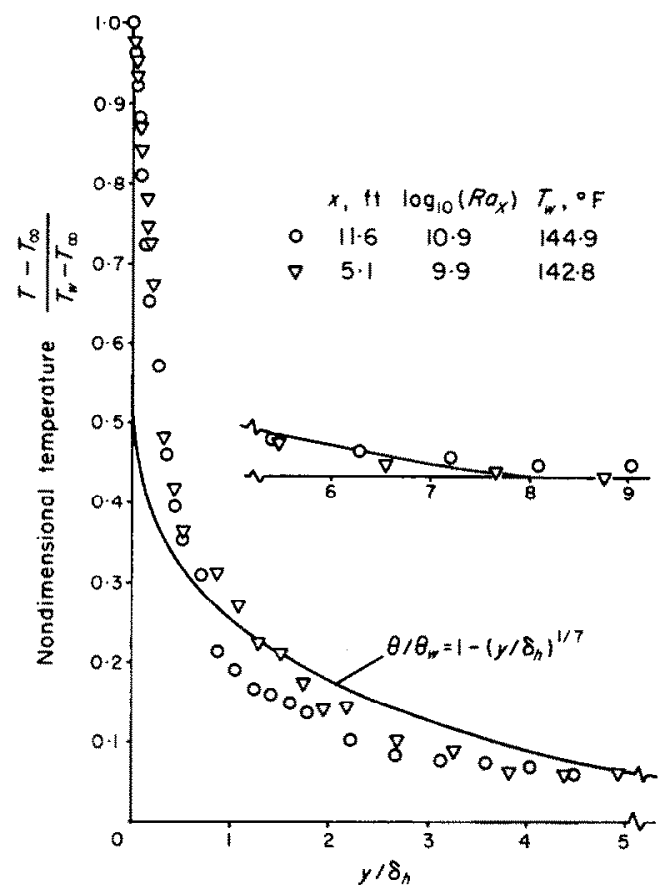

FIG. 4. Normalized experimental data and power-law profile.

[12] in the turbulent regimes. However, it can be shown that the rather coarse thermometer employed by Griffiths and Davis was subject to large errors due to conduction away from the sensitive element into its cooler supports. Figure 5 demonstrates this. Here the laminar results of Griffiths and Davis are compared with the Pohlhausen-Ostrach theory. It is easily seen that similar errors in the turbulent regime could provide support for equation (2).

Figure 4 demonstrated the inadequacy of the power-law concept for turbulent natural convection data. Turning now to another technique of correlation, consider Fig. 6 . There the results of Fujii [5] for convection in liquids are compared at similar Rayleigh numbers. The agreement is rather poor, and gives little credence to the use of Fujii's correlation for fluids of Prandtl numbers different from those used by him. (It should also be noted that because of its physical dimensions, Fujii's cylindrical apparatus possibly produced a significant curvature effect.) That the correlation variable Fujii

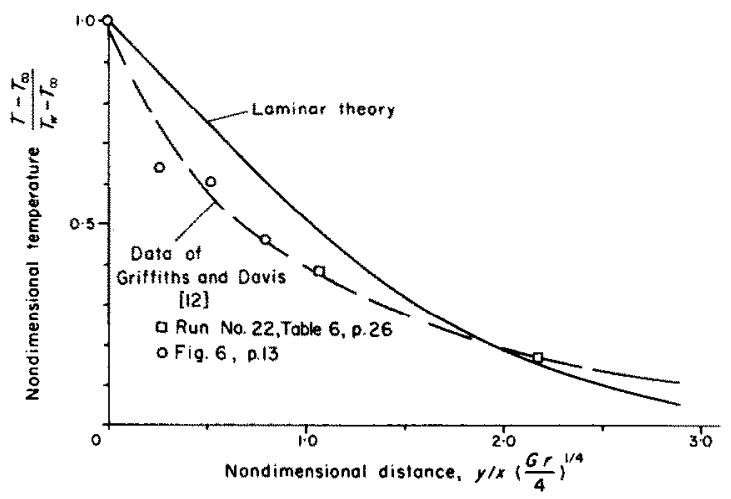

FIG. 5. Laminar data of Griffiths and Davis.

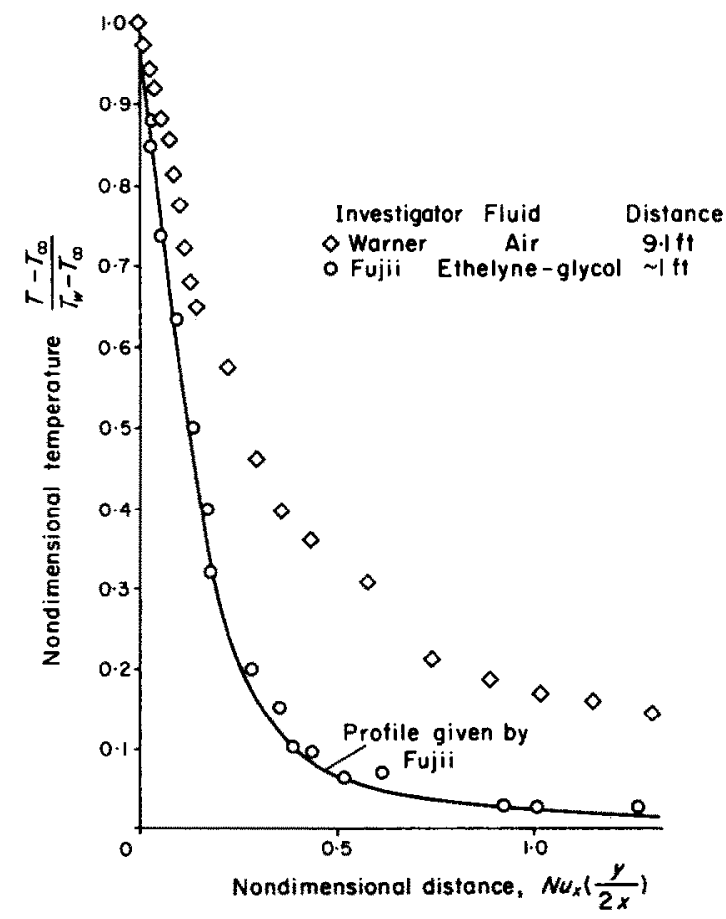

FiG. 6. Turbulent data of Fujii compared to that of the present experiment. 
suggested $\left(y N u_{x} / 2 x\right)$ is not unreasonable for the present turbulent data will be obvious when it is seen below that the local Nusselt number is approximately linear in distance over the turbulent range.

In fact, this similarity of the profiles in the natural coordinate $y$ is quite surprising. Figure 7 shows laminar and turbulent profiles plotted in this way. The close resemblance among laminar and turbulent profiles over a limited range is obvious. The fully turbulent profiles occupy a quite narrow band throughout the range of Rayleigh numbers measured. Of course, the temperature very near the wall reflects the expected non-similar trends, as shown earlier in Fig. 3.

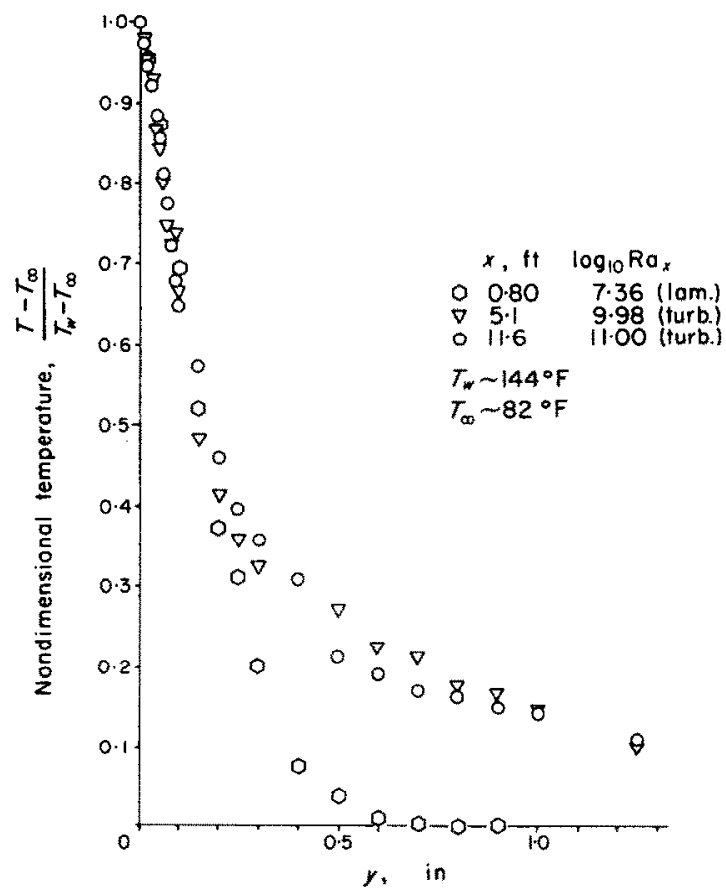

Fig. 7. Turbulent and laminar profiles at moderate distances from the wall.

It may be concluded from these measurements that the natural coordinate $y$ is perhaps the most adequate "similarity" variable for the turbulent case. From what is known about the lack of similarity in turbulent forced convection
[13] it is unlikely that a similarity parameter giving a more satisfactory agreement will be found.

\section{HEAT TRANSFER AT THE WALL}

The subdivided plate employed in these experiments made it possible to measure local heat flux rates with good accuracy for uniform plate temperature. The results of the measurements are shown below, compared to the correlations of McAdams, Bayley, and Eckert and Jackson $[3,4,8]$. The Ostrach theory is also presented. In all tests, the experimental heat inputs were corrected for radiation and insulation losses. The correction, uniform in $x$ in each case, was calculated by obtaining a regression fit of the laminar range data to the Ostrach result. Experimental data were also corrected for temperature stratification in the ambicnt by employing the local measured temperature difference for computation at each section. Before examination of the present heat-transfer data is undertaken, it is appropriate to be aware of the precautions employed to assure their reliability. Besides the verification tests mentioned above, which gave assurance of a properly functioning apparatus, reproducibility checks on the heat flux data were made. Readings taken on different days showed less than 3 per cent change in the recorded temperatures and power levels. Further, eighty-two turbulent data points were employed in the verification of the recommended correlation.

Of immediate interest here is the comparison on customary terms of the experimental Nusselt number vs. Rayleigh number results with the results presented and correlated by others. Figures 8 and 9 give graphical representation to these data. Figure 8 demonstrates the good agreement of the present work with the theory in the laminar range, but shows poor representation of the better-known correlations for the turbulent case by the turbulent data. Figure 9 describes the turbulent data, demonstrating the excellent agreement which was found with the correlation of Bayley. It shows two correlations, 
together with the present data and flat plate data for turbulent natural convection from the literature $[6,12]$. The agreement with the data of Saunders is good. The poorer agreement with other data suggests a need for greater insight into the data and their sources.

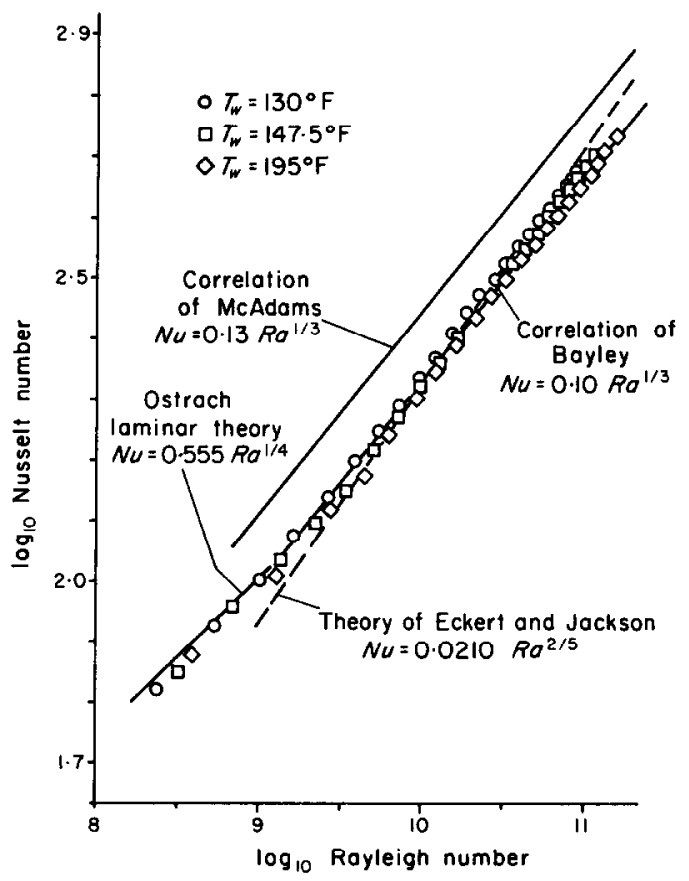

FIG. 8. Experimental heat-transfer data.

The natural convection phenomenon has been stated or tacitly assumed by most investigators to be two-dimensional flow field. Aside from the obvious departures from this picture introduced by random turbulence, further considerations regarding the mean flow, as they affect the assumptions made by many authors, deserve close attention. Turbulence in a free convection boundary layer is capable of encouraging two kinds of three-dimensionalities. The most obvious effect is that each lump of fluid is subject to random motion in the third dimension, even though no average potential exists to encourage a mean flow in this dimension. By statistical treatment of the flow, it is possible to visualize the real case in terms of a two-dimensional model. The more subtle effect of concern here is the increased mixing and heat transfer that may be expected to attend the turbulent motion. The sidewise entrainment inspired by this increased mixing has introduced unexpected errors into some of the published data.

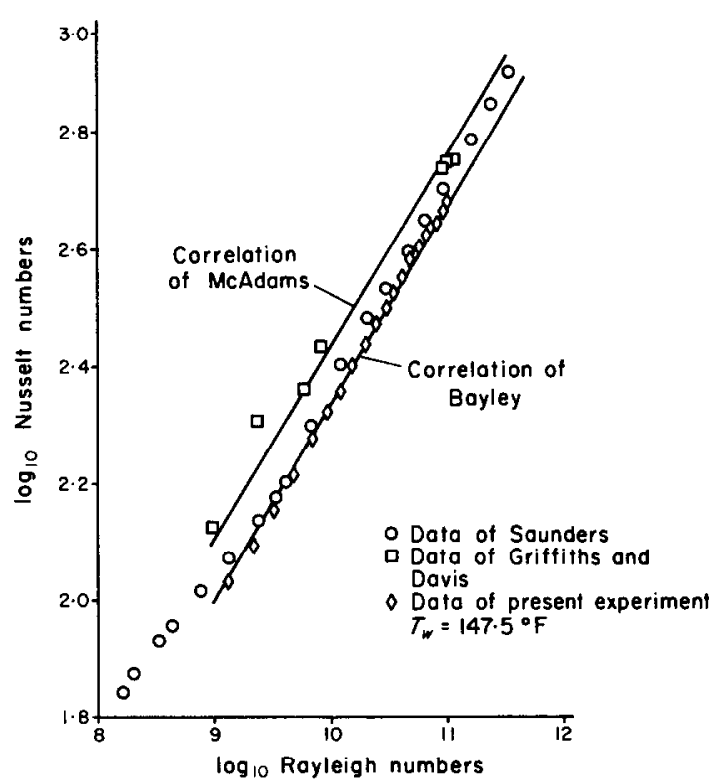

FiG. 9. Comparison of present data with data from literature.

A truly two-dimensional flow field may be realized approximately in several ways. (One of the ways in which a parallel two-dimensional flow is commonly approximated is by the use of a vertical cylinder of sufficiently large diameter. For the boundary-layer thicknesses considered here, this was not economically feasible.) The most common experimental means of approximating two-dimensional rectangular coordinate flow in natural convection is by the use of a wide flat plate. It is important to understand the effect that would be seen if the ratio of the boundary-layer thickness to plate width were to become too large. Although some of the published investigations did not report 
sufficient data to allow an estimate of this ratio, a good example of the problem is given by the data of Griffiths and Davis. In their work, a vertical sectioned plate of dimensions about $2 \times 9 \mathrm{ft}$ was used for most of the turbulent measurements reported. The data reported indicated a thermal boundary-layer thickness of about 8 in near the top of the plate. Without side baffes in this geometrical situation, one might expect a sizeable increase in heat transfer over the truly two-dimensional case, due to the entrainment of cooler air from the sides of the plate.

In the opinion of the present authors, this is sufficient explanation for two things evident in Fig. 9. First, the disagreement of Griffiths and Davis' data with that of Saunders and the present experiment can be easily understood. Second. since the McAdams correlation was based upon the best available data of its time. it was also probably biased by the Griffiths and Davis results, and is understandably displaced in the direction of higher heat transfer.

Turning now to another interesting means of comparison, consider Fig. 10. Here is scen the advantage of a sectionalized test surface. The actual power input is compared with the correlations mentioned above. The trend of the data is much more obvious on this basis. Again, corrections have been made for insulation and radiation losses, and for thermal stratification of the ambient, as already discussed above. The correlations of McAdams, Eckert and
Jackson, and Bayley have been transformed to the local coordinates.

The agreement of the data with the correlation of Bayley is perhaps even more strikingly demonstrated here, where the smoothing effect of the logarithmic coordinates is absent. The degree of accuracy with which the correlation of Bayley represents the local heat flux in both trend and magnitude lends significant credence to its use for natural convection boundary layers involving air and similar gases.

\section{CONCLUSIONS}

Until quite recently, forced convection heat transfer was consistently treated analytically by means of either integral methods or direct application of Reynolds' analogy, with a strong empirical flavor in either case.

The work of Spalding [14] constituted a very satisfactory step toward a more direct analytical approach, employing a convenient summary of the physics of the turbulent motion in terms of the well-known law of the wall. Early in the present study, it was hoped that a similar technique might be brought into focus for the case of turbulent natural convection. This will necessarily wait until more information can be gained about the nature of the velocity field in the near vicinity of the wall, which waits in turn upon the development of a practicable technique for measurement of very low velocities. A significant contribution will be made to the present state of knowledge about turbulent heat

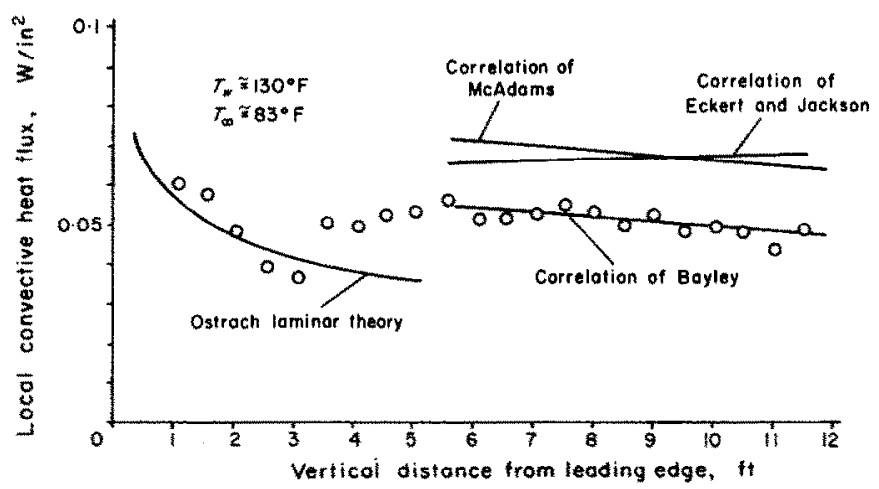

Frg. 10. Local heat fux as a function of plate distance. 
transfer when the velocity field is accurately measured.

The experimental results which were obtained in the present study allow the following conclusions.

(1) The correlations for heat transfer recommended by McAdams [8] and by Eckert and Jackson [3] are inferior to that of Bayley [4] for turbulent natural convection in air, although that of McAdams gives a good representation of the slope of the experimental curve.

(2) The 1/7 power temperature profile adopted for use in analyses of turbulent natural convection is definitely not accurate for that case. Its carlicr recommendations were probably based upon erroneous temperature readings.

(3) Except at the wall itself, the turbulent mean temperature profile is well represented on natural coordinates by a laminar profile over a great portion of the thermal layer.

(4) The primary effect of increased distance along the plate upon the temperature profiles appears to be a thickening of the thermal layer, with all profiles taking the same basic form for moderate distances from the wall.

Finally, there is a need for verification of the established correlation at Prandtl numbers different than that treated here, with primary emphasis upon the Prandtl number range encompassed by liquid rocket propellants.

\section{ACKNOWLEDGEMENTS}

The financial support provided by the Department of Mechanical Engineering and the Heat Transfer Laboratory, at the University of Michigan, is gratefully acknowledged. The technical counsel of Professors Clark, Hansen, and Kuethe of that institution was very helpful and is also much appreciated. The personal financial support provided by the National Science Foundation and by the National Aeronautics and Space Administration was most gratefully received. Thanks also to Mrs. Nancy Tippetts and the Department of Mechanical Engineering, Brigham Young University for special help in the preparation of the manuscript.

\section{REFERENCES}

1. E. Schmidt and W. Beckmann, Forsch. Geb. IngWes. 1, 391 (1930).

2. S. Ostrach, An analysis of laminar free-convection flow and heat transfer about a flat plate parallel to the direction of the generating body force, NACA TR 1111 (1953).

3. E. R. G. ECKeRt and T. W. JACKSON, Analysis of turbulent free-convection boundary layer on a flat plate, NACA TR 1015 (1951).

4. F. J. BAYLEY, An analysis of turbulent free-convection heat transfer, Proc. Instn Mech. Engrs 169(20), 361 (1955).

5. T. FUJI, Experimental studies of free convection heat transfer, Bull. J.S.M.E. 2(8), 555 (1959).

6. O. A. SAUNDERS, Effect of pressure upon natural convection in air, Proc. R. Soc. A157, 278 (1936).

7. M. JAKOB and W. LINKE, Heat transfer in boiling water, Forsch. Geb. IngWes. 4, 75 (1933).

8. W. H. McAdams, Heat Transmission, 3rd edn. McGrawHill, New York (1954).

9. C. Y. WARNER, Turbulent natural convection in air along a vertical flat plate, Ph.D. Thesis, University of Michigan, Ann Arbor, Michigan (December 1966).

10. D. G. Collis and M. J. Williams, Two-dimensional convection from heated wires at low Reynolds numbers, J. Fluid Mech. 6, 359 (1959).

11. D. J. Tritton, The use of a fibre anemometer in turbulent flows, J. Fluid Mech. 16, 269 (1963).

12. E. GRIfFiths and A. H. DAvis, The transmission of heat by radiation and convection, Spec. Rep. No. 9, Fd Invest. Bd D.S.I.R. (1922).

13. F. H. Clauser, The turbulent boundary layer, $A d v$. Appl. Mech, edited by H. L. DRYDEN and T. VON Kármán, Vol. IV, p. 1. Academic Press, Ncw York (1956).

14. D. B. Spalding, Heat transfer to turbulent stream from a surface with a stepwise discontinuity in wall temperature, International Developments in Heat Transfer, Vol. II, p. 439. Am. Soc. Mech. Engrs-Inst. Mech. Engrs, New York (1961).

Résumé-Une recherche expérimentale de la convection naturelle turbulente dans l'air est décrite. Les résultats de cette étude montrent un bon accord avec des recherches antérieures et un accord remarquable avec la relation théorique de Bayley: (4)

$$
N u=0,10 R a^{t}
$$

pour des nombres de Rayleigh allant jusqu'a $10^{12}$.

Des mesures complètes du champ de température indiquent une bonne similitude pour les profils de température lorsqu'on les compare en utilisant la coordonnée physique y. L'emploi de profils de températures en puissance n'est pas désirable dans le cas de la convection naturelle turbulente. 
Zusammenfassung-Es wird eine experimentelle Untersuchung der turbulenten freien Konvektion für Luft beschrieben. Die Ergebnisse dieser Arbeit zeigten gute Obereinstimmung mit früheren Untersuchungen und bemerkenswerte Obereinstimmung mit der analytischen Korrelation von Bayley [4]

$$
N u=0,10 R a^{3}
$$

für Rayleigh-Zahlen bis $10^{12}$.

Umfangreiche Messungen des Temperaturfeldes zeigen gute Ähnlichkeit der Temperaturprofile wenn sie auf Grund der natürlichen Koordinate y verglichen werden. Die Verwendung von Temperaturprofilen die einem Potenzgesetz gehorchen erweist sich für den Fall turbulenter freier Konvektion als ungünstig.

Анвотадня-Результаты әкспериментального исследования обнаруживают хорошее согласие $c$ ранее проведенными исследованиям и и примечательное совпадение с аналитической формулой Беилли [4]:

для значений критерия Релея до $10^{12}$

$$
N u=0,10 R a^{\frac{3}{3}}
$$

Обширные ивмерения температурного поля вынвили подобие температурных профилећ, построенных с помощью естественной координаты $y$. Отмечается нецелесообравность степенных аппроксимаций температурных профилей для случая турбулентной естественнои конвекции. 